\title{
Age Estimation from Ossification of the Medial Clavicular Epiphysis by Computed Tomography
}

\author{
Estimación de la Edad de Osificación de la Epífisis Medial \\ Clavicular por Tomografía Computadorizada
}

Doaa A. El Morsi"; Hend M. Abo El-Atta*; Merit EIMaadawy ${ }^{* *}$; Ahmed M. Tawfik ${ }^{* *}$ \& Nihal M. Batouty ${ }^{* *}$

EL MORSI, D. A.; EL-ATTA, H. M. A.; ELMAADAWY, M.; TAWFIK, A. M. \& BATOUTY, N. H. Age estimation from ossification of the medial clavicular epiphysis by computed tomography. Int. J. Morphol., 33(4):1419-1426, 2015.

SUMMARY: The current study intended to evaluate the accuracy of age estimation from the development of the medial clavicular epiphysis (sternal end of the clavicle) in Egyptian population using computed tomography (CT) and to develop a discriminant formula that can be used in Egyptians. The study was conducted on 142 subjects ( 84 males and 58 females) after taken informed consent. They were subjected to multi-slice CT on the medial end of clavicles of both sides. The results revealed that the age of non - union was seen at 8-17 years; incomplete union at 15-20 years and complete union was seen at 20 years. It is concluded that the ossification of medial clavicular end could be used for age estimation. Also CT is a good visualization tool to be used. Regression analysis for each and both clavicles in both sexes is specific to Egyptian population and should be used after validation of the results in other ones. The study recommended using stage 1 to be $<17$ years; stage 2 to be $>15$ years; Stage 3 to be $>15$ years; stage 4 of maturation to be $>19$ years and stage 5 to be $>21$ years.

KEY WORDS: Forensic science; Age estimation; Ossification status; Medial clavicular epiphysis; Sternal end of the clavicle; Identification; Computed tomography.

\section{INTRODUCTION}

Age estimation of unknown people is increasingly essential part of forensic medical practice and research (Cunha et al., 2009). It is legitimately vital to identify individuals of age 18 years by forensic professionals due partially to developing pressure from legal systems around the globe that give more accurate age estimations for the increasing numbers of undocumented individuals, and to aid in the definitive identification of casualties of mass disasters (Schmeling et al., 2006).

Moreover; assessment of the clavicle by means of CT is frequently utilized as a part of legal age diagnostics because, as a modern cross-sectional imaging method, it has various advantages contrasted with traditional radiography, for instance no superimposition impacts of other anatomic structures (Kellinghaus et al., 2010a). However, Muhler et al. (2006) had the capacity to demonstrate that different slice thicknesses have noteworthy impact on the accuracy of forensic stage assessments of the medial clavicular epiphysis (sternal end of the clavicle). To date, a slice thickness not larger than $1 \mathrm{~mm}$ is recommended to guarantee the most extreme of accuracy and diagnostic reliability (Schulz et al. 2013)..

The current study is conducted to evaluate the accuracy of age estimation from the development of the medial clavicular epiphysis using CT and to develop a discriminant formula that can be used in Egyptians.

\section{SUBJECTS AND METHOD}

Samples. This study was conducted on a total of 142 Egyptian subjects (84 males and 58 females) of known birthdate and sex. They were subjected to a high resolution multi-slice computed tomography (CT) after taken written informed consent. Protocol of the study was approved by Ethical Committee of Faculty of Medicine, Mansoura University.

\footnotetext{
* Department of Forensic Medicine \& Clinical Toxicology, Mansoura Faculty of Medicine, Mansoura University, Egypt.

** Diagnostic Radiology Department, Mansoura Faculty of Medicine, Mansoura University, Egypt.
} 
Computed tomography films were provided by a private radiologist (Hyperion X7, MYRAY - Imola, Italy). The exclusion criteria were: Patients with diseases that may affect bone development including previous fractures of the clavicle, chronic illness, and patients who were treated by steroids, chemotherapy, or immunosuppressive drugs. Data on nutrition or socioeconomic status was unattainable.

Measurements. The imaging protocol consists of high resolution thin slice CT scan captures 1-2 mm thick slices, either covering only the region of sterno-clavicular joint or covering this region as a part of already requested scan for chest or head and neck. Muhler et al. and Schulz et al. (2013) advised slice thickness of $1 \mathrm{~mm}$ in order to achieve best possible results and maximum accuracy of age estimation. Also they stated that the resolution along the longitudinal axis is inversely proportional to the slice thickness, as the slice thickness increases the resolution will be decreased, which may partly or fully mask the fine anatomical structures.

The clavicular epiphyses at sternal end of the clavicle will be examined in all slices and evaluated in axial multiplanner reformates, where the most representative slice for each clavicle will be scored. All images for each case will be saved in separate files with an anonymous case number. Each case file consists of two images each for the left and right clavicles, both coronal and axial views. If both left and right clavicles of same case appear intact and are able to be scored, a comparison would be made to determine the degree of right/left side developmental asymmetry.

Two expert radiologists will interpret the images separately, each scoring 20 case images per each set. Both examiners routinely determine skeletal maturation using clavicles on CT as a part of preoperative evaluation for chest wall deformity and scoliosis. The stages were as follows as described by Kellinghaus et al. (2010a) (Fig. 1.): Stage 1: Non-ossified epiphysis; Stage 2: Ossified epiphysis, growth plate is not ossified; Stage 3: Growth plate is partially fused; Stage 4: Complete union of the epiphysis and metaphysis; epiphyseal scar is visible and Stage 5: Complete union of the epiphysis and metaphysis; epiphyseal scar is no longer visible. Right and left clavicles were staged separately. The images were scored by consensus. Both readers were blinded for patient's ages. In cases where a different maturation status occurred between right and left clavicles, the more advanced side was used for analysis.

Statistical Analysis. All statistical analysis were performed using SPSS (statistical package for social science, Inc, Chicago, IL) program version 17. The qualitative data were presented in the form of number and percentage. The quantitative data were presented in the form of minimum; maximum and mean \pm Standard Deviation (SD). The analysis of the data was done to test statistical significant difference between groups. For quantitative date, student t-test was used to compare between two groups. Spearman correlation was done to detect the association between two variables. Linear logistic regression was done to predict unknown variable (age) by using CT measurements significant in univariate analysis. Tests for inter - and intra examiner reliability were assessed using the Kappa measure of agreement. Significance was considered at $p$ value $<0.05$ at confidence interval $95 \%$.

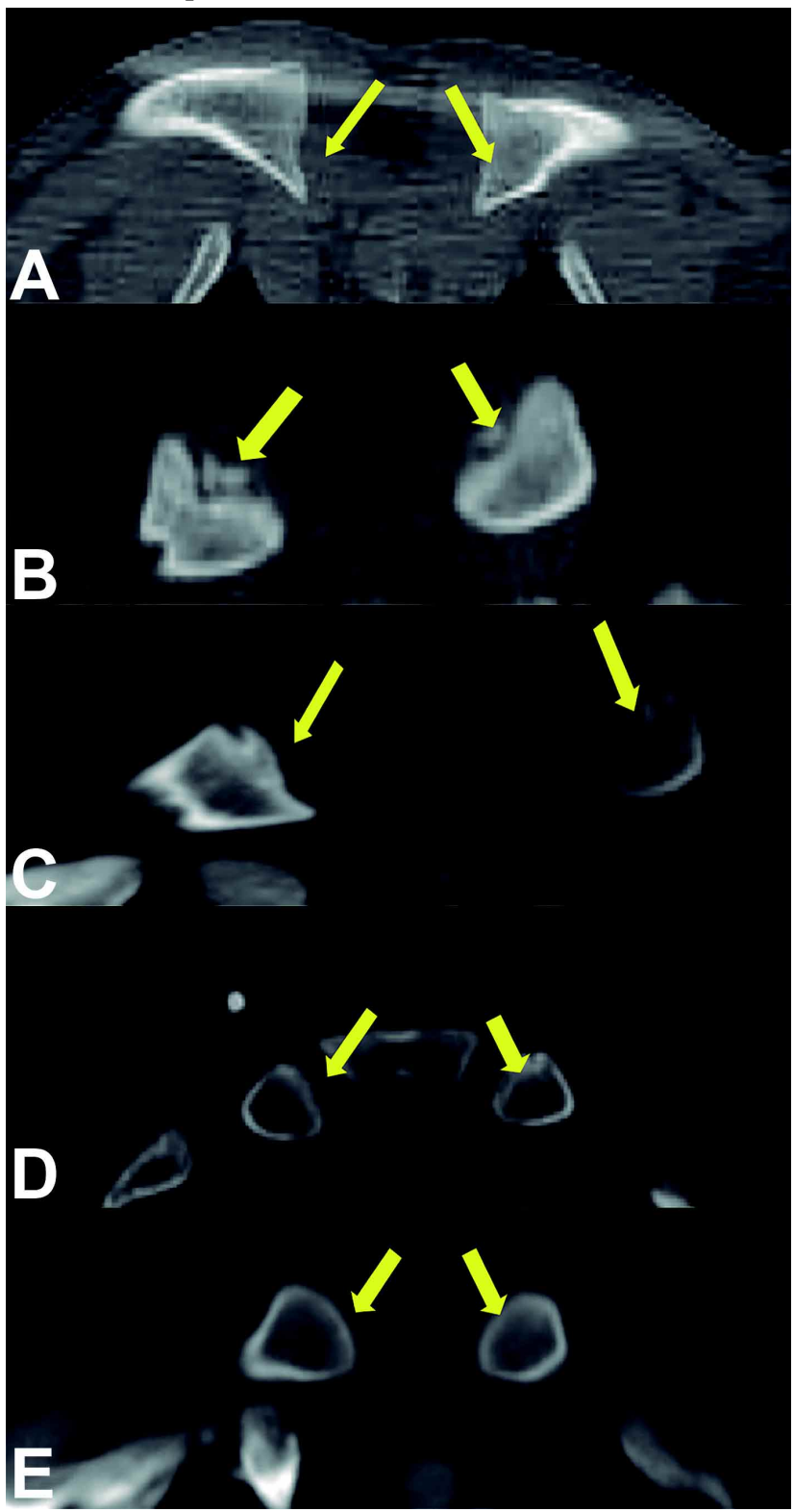

Fig. 1. Stages of union of medial clavicular epiphyses. A. Stage 1: Non-ossified epiphysis. B. Stage 2: Ossified epiphysis, growth plate is not ossified. C. Stage 3: Growth plate is partially fused. D. Stage 4: Complete union of the epiphysis and metaphysis; epiphyseal scar is visible. E. Stage 5: Complete union of the epiphysis and metaphysis; epiphyseal scar is no longer visible. 


\section{RESULTS}

Intra - examiner testing revealed a Kappa measure of agreement of 0.854 . Inter - examiner testing proved an

Table I. Descriptive data of all studied subjects $(n=142)$.

\begin{tabular}{lccccc}
\hline Sex & Mean \pm SD & Min & Max & t & p \\
\hline $\begin{array}{l}\text { Males }(\mathrm{n}= \\
(59.2 \%)\end{array}$ & $20.940 \pm 4.855$ & 15 & 30 & & \\
$\begin{array}{l}\text { Females } \\
(40.8 \%)\end{array}$ & $22.206 \pm 5.070$ & 8 & 30 & 1.5 & 0.136 \\
$\begin{array}{l}\text { Total }(\mathrm{n}= \\
(100 \%)\end{array}$ & $21.457 \pm 4.966$ & 8 & 30 & & \\
\hline
\end{tabular}

$\mathrm{SD}=$ standard deviation; $\mathrm{Min}=$ minimum; Max $=$ maximum; $\mathrm{p}$ is significant $<0.05$.

Table II. Age by sex distribution of all studied subjects $(\mathrm{n}=142)$.

\begin{tabular}{lccc}
\hline Age (years) & Males (n) & Females (n) & Total (n) \\
\hline 8 & 0 & 2 & $\mathbf{2}$ \\
15 & 12 & 2 & $\mathbf{1 4}$ \\
16 & 8 & 2 & $\mathbf{1 0}$ \\
17 & 4 & 2 & $\mathbf{6}$ \\
18 & 2 & 4 & $\mathbf{6}$ \\
19 & 12 & 6 & $\mathbf{1 8}$ \\
20 & 10 & 4 & $\mathbf{1 4}$ \\
21 & 8 & 4 & $\mathbf{1 2}$ \\
22 & 2 & 4 & $\mathbf{6}$ \\
23 & 4 & 8 & $\mathbf{1 2}$ \\
24 & 3 & 0 & $\mathbf{3}$ \\
25 & 1 & 4 & $\mathbf{5}$ \\
26 & 0 & 2 & $\mathbf{2}$ \\
27 & 6 & 0 & $\mathbf{6}$ \\
28 & 2 & 8 & $\mathbf{1 0}$ \\
29 & 0 & 2 & $\mathbf{2}$ \\
30 & 10 & 4 & $\mathbf{1 4}$ \\
Total & 84 & 58 & $\mathbf{1 4 2}$ \\
\hline
\end{tabular}

agreement of 0.753 . Both of these readings state good to excellent agreement. Developmental differences between right and left clavicles is not statistically significant in either males $(\mathrm{p}=0.08)$ or females $(\mathrm{p}=0.41)$.

The mean+SD age of the studied subjects was $21.457 \pm 4.966$ years (ranges from 8 to 30 years). Males ( 84 cases) represent $59.2 \%$ with $20.94 \pm 4.855$ years; while females ( 58 cases) represent $40.8 \%$ with $22.206 \pm 5.070$ years. Table I demonstrates the descriptive data of all studied subjects $(n=142)$.

The majority of males are in the ages of 15 and 19 years (12 cases each) followed by 10 cases in ages 20 and 30 . While most of females are in ages 23 \& 28 years (8 cases each); followed by age 19 years ( 6 cases). Table II reveals age by sex distribution of all studied subjects $(n=142)$.

Table III shows summary statistics (minimum, maximum, mean $\pm \mathrm{SD}$ ) and comparison for all stages between both sexes $(n=142)$. Also there is no significant difference between both sexes as respect any stage (except stage 1 at right side).

The highest frequencies are observed in both 5 th and 3rd stages in males (26.2\% and $22.6 \%$ for right side) and (27.4\% and $22.6 \%$ for left side) respectively. Also in females 5 th stage followed by 3rd stage have the highest frequencies (44.83\% and $27.58 \%$ for right side) and (37.93\% and $24.14 \%$ for left side) respectively. Tables IV show the frequency distribution of different stages of epiphyseal union in clavicles of either side in all studied subjects $(n=142)$.

Age distribution of different stages of epiphyseal union in right and left clavicles in both sexes in all studied subjects $(n=142)$ is show in Table V. Stage 1 starts at 8 years in females and between $15-17$ years in males. While;

Table III. Summary statistics (minimum, maximum, mean + SD) and comparison for all stages between both sexes $(n=142)$.

\begin{tabular}{|c|c|c|c|c|c|c|c|c|c|c|c|c|}
\hline \multirow{3}{*}{ Side } & & \multirow{3}{*}{ Sex } & \multicolumn{10}{|c|}{ Stages } \\
\hline & & & \multicolumn{2}{|c|}{$1^{\text {st }}$} & \multicolumn{2}{|c|}{ 2nd } & \multicolumn{2}{|c|}{$3 r^{d}$} & \multicolumn{2}{|c|}{$4 t^{\mathrm{h}}$} & \multicolumn{2}{|c|}{$5^{\text {th }}$} \\
\hline & & & Min & Max & Min & Max & Min & Max & Min & Max & Min & Max \\
\hline \multirow{6}{*}{ Rt } & \multirow{6}{*}{$\begin{array}{l}\text { Range } \\
\text { Mean } \pm \\
\text { Range } \\
\text { Mean } \pm\end{array}$} & \multirow{2}{*}{ M } & 15 & 17 & 15 & 20 & 15 & 23 & 20 & 28 & 21 & 30 \\
\hline & & & \multicolumn{2}{|c|}{$15.62 \pm 0.71$} & \multicolumn{2}{|c|}{$17.66 \pm 1.87$} & \multicolumn{2}{|c|}{$19.47 \pm 2.19$} & \multicolumn{2}{|c|}{$22.26 \pm 3.32$} & \multicolumn{2}{|c|}{$26.95 \pm 3.27$} \\
\hline & & $\mathbf{F}$ & 8 & 8 & 16 & 18 & 15 & 23 & 19 & 23 & 22 & 30 \\
\hline & & & \multicolumn{2}{|c|}{$8 \pm 0$} & \multicolumn{2}{|c|}{$17.00 \pm 1.15$} & \multicolumn{2}{|c|}{$19.00 \pm 2.36$} & \multicolumn{2}{|c|}{$21.00 \pm 1.49$} & \multicolumn{2}{|c|}{$26.53 \pm 2.67$} \\
\hline & & $\mathbf{t}$ & \multicolumn{2}{|c|}{14.60} & \multicolumn{2}{|c|}{0.66} & \multicolumn{2}{|c|}{0.61} & \multicolumn{2}{|c|}{1.12} & \multicolumn{2}{|c|}{0.48} \\
\hline & & $\mathbf{p}$ & \multicolumn{2}{|c|}{$0.00 *$} & \multicolumn{2}{|c|}{0.51} & \multicolumn{2}{|c|}{0.54} & \multicolumn{2}{|c|}{0.27} & \multicolumn{2}{|c|}{0.63} \\
\hline \multirow{5}{*}{ Lf } & Range & M & 15 & 15 & 15 & 20 & 17 & 23 & 20 & 30 & 20 & 30 \\
\hline & Mean \pm & & \multicolumn{2}{|c|}{$15.00 \pm 0.00$} & \multicolumn{2}{|c|}{$16.90 \pm 1.74$} & \multicolumn{2}{|c|}{$19.68 \pm 1.79$} & \multicolumn{2}{|c|}{$24.71 \pm 3.6$} & 25.2 & -4.28 \\
\hline & Range & $\mathbf{F}$ & 8 & 8 & 16 & 18 & 15 & 21 & 19 & 30 & 22 & 30 \\
\hline & Mean \pm & & & & 17. & 1.15 & 18.4 & $=1.91$ & 22.6 & \pm 3.22 & 26.5 & 2.48 \\
\hline & & $\mathbf{t}$ & & & & & & & & & & \\
\hline
\end{tabular}

$\mathrm{Rt}=$ right; $\mathrm{Lf}=$ left; $\mathrm{M}=$ male; $\mathrm{F}=$ female; $\mathrm{Min}=$ minimum; $\mathrm{Max}=$ maximum; $\mathrm{SD}=$ standard deviation; $\mathrm{p}$ is significant $<0.05$. 
Table IV. Frequency distribution of different stages of epiphyseal union in clavicles of either side in all studied subjects $(n=142)$

\begin{tabular}{lcccccc}
\hline Sex & Side & $\mathbf{1 s}^{\mathbf{t}} \mathbf{n}(\mathbf{\%})$ & $\mathbf{2 n d}^{\mathbf{n d}(\mathbf{\%})}$ & $\begin{array}{c}\text { Stages } \\
\mathbf{3 r}^{\mathbf{d}} \mathbf{n}(\%)\end{array}$ & $\mathbf{4}^{\mathbf{h}} \mathbf{n}(\mathbf{\%})$ & $\mathbf{5}^{\text {th n }} \mathbf{( \% )}$ \\
\hline Males & Rt & $16(19 \%)$ & $12(14.3 \%)$ & $19(22.6 \%)$ & $15(17.9 \%)$ & $22(26.2 \%)$ \\
$(\mathbf{n = 8 4})$ & Lf & $8(9.5 \%)$ & $20(23.8 \%)$ & $19(22.6 \%)$ & $14(16.7 \%)$ & $23(27.4 \%)$ \\
Females & Rt & $2(3.45 \%)$ & $4(6.9 \%)$ & $16(27.58 \%)$ & $10(17.24 \%)$ & $26(44.83 \%)$ \\
$(\mathbf{n = 5 8})$ & Lf & $2(3.45 \%)$ & $4(6.9 \%)$ & $14(24.14 \%)$ & $16(27.58 \%)$ & $22(37.93 \%)$ \\
\hline
\end{tabular}

$\mathrm{Rt}=$ right; $\mathrm{Lf}=$ left.

Table V. Age distribution of different stages of epiphyseal union in right and left clavicles in both sexes in all studied subjects $(n=142)$.

\begin{tabular}{|c|c|c|c|c|c|c|c|c|c|c|c|c|}
\hline \multirow[t]{2}{*}{ Age } & \multirow[t]{2}{*}{ Sex } & \multirow{2}{*}{$\begin{array}{c}\text { Total n } \\
\text { of } \\
\text { cases }\end{array}$} & \multicolumn{2}{|c|}{$1^{\text {st }}(\mathrm{n})$} & \multicolumn{4}{|c|}{$\begin{array}{c}\text { Stages } \\
3^{\text {rd }} \text { (n) }\end{array}$} & \multicolumn{2}{|c|}{$4^{\text {th }}(\mathrm{n})$} & \multicolumn{2}{|c|}{$5^{\text {th }}(\mathrm{n})$} \\
\hline & & & Rt & Lf & Rt & Lf & Rt & Lf & Rt & Lf & Rt & Lf \\
\hline \multirow{2}{*}{8} & $\mathrm{M}$ & 0 & - & - & - & - & - & - & - & - & - & - \\
\hline & $\mathrm{F}$ & 2 & 2 & 2 & - & - & - & - & - & - & - & - \\
\hline \multirow{2}{*}{15} & $\mathrm{M}$ & 12 & 8 & 8 & 2 & 4 & 2 & - & - & - & - & - \\
\hline & $\mathrm{F}$ & 2 & - & - & - & - & 2 & 2 & - & - & - & - \\
\hline \multirow{2}{*}{16} & $\mathrm{M}$ & 8 & 6 & - & 2 & 8 & - & - & - & - & - & - \\
\hline & $\mathrm{F}$ & 2 & - & - & 2 & 2 & - & - & - & - & - & - \\
\hline \multirow{2}{*}{17} & $\mathrm{M}$ & 4 & 2 & - & 2 & 2 & - & 2 & - & - & - & - \\
\hline & $\mathrm{F}$ & 2 & - & - & - & - & 2 & 2 & - & - & - & - \\
\hline \multirow{2}{*}{18} & $\mathrm{M}$ & 2 & - & - & - & - & 2 & 2 & - & - & - & - \\
\hline & $\mathrm{F}$ & 4 & - & - & 2 & 2 & 2 & 2 & - & - & - & - \\
\hline \multirow{2}{*}{19} & $\mathrm{M}$ & 12 & - & - & 4 & 4 & 8 & 8 & - & - & - & - \\
\hline & $\mathrm{F}$ & 6 & - & - & - & - & 4 & 4 & 2 & 2 & - & - \\
\hline \multirow{2}{*}{20} & $\mathrm{M}$ & 10 & - & - & 2 & 2 & - & - & 8 & 2 & - & 6 \\
\hline & $\mathrm{F}$ & 4 & - & - & - & - & 2 & 2 & 2 & 2 & - & - \\
\hline \multirow[t]{2}{*}{21} & $\mathrm{M}$ & 8 & - & - & - & - & 4 & 4 & 2 & 2 & 2 & 2 \\
\hline & $\mathrm{F}$ & 4 & - & - & - & - & 2 & 2 & 2 & 2 & - & - \\
\hline \multirow{2}{*}{22} & $\mathrm{M}$ & 2 & - & - & - & - & 1 & 1 & 1 & 1 & - & - \\
\hline & $\mathrm{F}$ & 4 & - & - & - & - & - & - & 2 & 2 & 2 & 2 \\
\hline \multirow{2}{*}{23} & $\mathrm{M}$ & 4 & - & - & - & - & 2 & 2 & - & - & 2 & 2 \\
\hline & $\mathrm{F}$ & 8 & - & - & - & - & 2 & - & 2 & 6 & 4 & 2 \\
\hline \multirow[t]{2}{*}{24} & $\mathrm{M}$ & 3 & - & - & - & - & - & - & - & 3 & 3 & - \\
\hline & $\mathrm{F}$ & 0 & - & - & - & - & - & - & - & - & - & - \\
\hline \multirow{2}{*}{25} & $\mathrm{M}$ & 1 & - & - & - & - & - & - & - & - & 1 & 1 \\
\hline & $\mathrm{F}$ & 4 & - & - & - & - & - & - & - & - & 4 & 4 \\
\hline \multirow[t]{2}{*}{26} & $\mathrm{M}$ & 0 & - & - & - & - & - & - & - & - & - & - \\
\hline & $\mathrm{F}$ & 2 & - & - & - & - & - & - & - & - & 2 & 2 \\
\hline \multirow[t]{2}{*}{27} & $\mathrm{M}$ & 6 & - & - & - & - & - & - & 2 & 2 & 4 & 4 \\
\hline & $\mathrm{F}$ & 0 & - & - & - & - & - & - & - & - & - & - \\
\hline \multirow[t]{2}{*}{28} & $\mathrm{M}$ & 2 & - & - & - & - & - & - & 2 & 2 & - & - \\
\hline & $\mathrm{F}$ & 8 & - & - & - & - & - & - & - & - & 8 & 8 \\
\hline \multirow{2}{*}{29} & $\mathrm{M}$ & 0 & - & - & - & - & - & - & - & - & - & - \\
\hline & $\mathrm{F}$ & 2 & - & - & - & - & - & - & - & - & 2 & 2 \\
\hline \multirow[t]{2}{*}{30} & $\mathrm{M}$ & 10 & - & - & - & - & - & - & - & 2 & 10 & 8 \\
\hline & $\mathrm{F}$ & 4 & - & - & - & - & - & - & - & 2 & 4 & 2 \\
\hline
\end{tabular}

$\mathrm{Rt}=$ right $\mathrm{Lf}=$ left$; \mathrm{M}=$ male; $\mathrm{F}=$ female.

stage 2 shows up at age $15-20$ years in males and $16-18$ years in females (exception of age 17). Moreover; stage 3 starts at 15-23 years in both males and females. Regarding $4^{\text {th }}$ stage, it appears at 20-30 years in males and 19-30 years in females. Lastly, 5th stage starts at 20-30 years in males while in females stage 5 starts at $22-30$ years. 


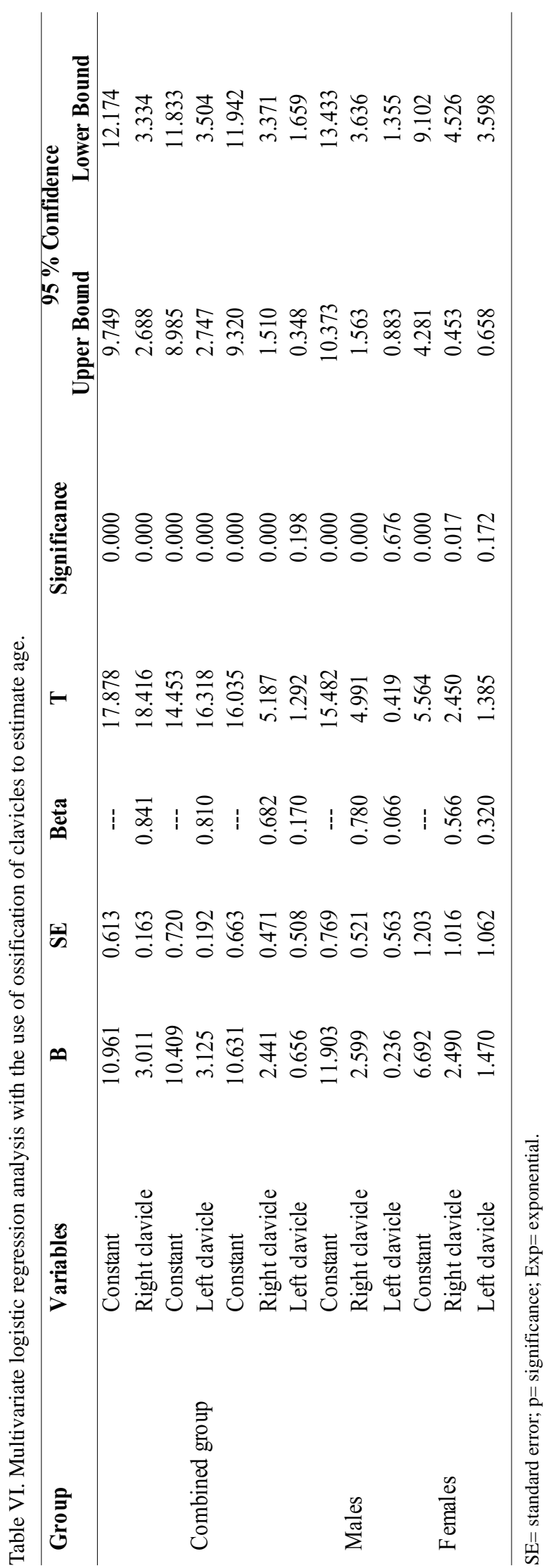

Table VI reveals the multivariate logistic regression analysis with the use of ossification of clavicles to estimate age. Age (Y) could be estimated using the following equations in both sexes; males and females respectively.

Age $($ Combined group $)=10.961+3.011 \mathrm{X}$ right clavicle; $10.409+3.125 \mathrm{X}$ left clavicle; $10.631+2.441 \mathrm{X}$ right clavicle $+0.656 \mathrm{X}$ left clavicle.

Age $($ Male $)=11.903+2.599 \mathrm{X}$ right clavicle $+0.236 \mathrm{X}$ left clavicle.

Age $($ Female $)=6.692+2.490 \mathrm{X}$ right clavicle $+1.470 \mathrm{X}$ left clavicle.

$\mathrm{X}$ is the stage of ossification of clavicle.

\section{DISCUSSION}

The goal of the present study is evaluate the accuracy of age estimation from the development of the medial clavicular epiphysis using computed tomography (CT) and to develop a discriminant formula that can be used in Egyptians. The results revealed no significant differences between males and females (except for stage 1) (Table III) or right and left sides as regard age of ossification of medial end clavicles as mentioned before.

This was in concurrence with studies of Kellinghaus et al. (2010a) (except for stage 2); Kellinghaus et al. (2010b); Schulze et al. (2006); and Wittschieber et al. (2014) (except for stages 2b; 3; 3c and 4) in Germany; Bassed et al. (2011) in Australia; El Gerby et al. (2013) in Egypt (except for stages 1, 3 and 5); Pattamapaspong et al. (2015) in Thailand (except in stage 2); Singh \& Chavali (2011) and Gakhar et al. (2014) in India; Brown et al. (2013) in Ghana (except in stages 2, 3 and 4) and Garamendi et al. (2011) in Spain. They regarded no significant distinction of right and left sides or both sexes.

In addition; by concentrating on the age of ossification of medial clavicular ends in both sexes and both sides; the present results revealed that the means of chronological age are consistently increase with increasing stage, this demonstrates good correlation between stages and chronological age. Stage 1 did not present in the majority after 15 years and in some cases after 17 years; while stage 2 did not show up after age 20 years; maximum age for stage 3 was 23 years and 30 years for stage 4 and not before 19 years. While complete union of stage 5 did not start before 20 years. The differences between males and females in the age of ossification could be related to socio - economic conditions. 
Subjects from lower economic conditions tend to have delayed fusion of their epiphyses when compared to subjects from higher socio-economic due to poor nutrition. The range of ossification of stage 1 could not be judged accurately in both sexes as ages from 9-14 years were missed in the sample (Tables III, IV, V and VI).

This was in inconsistency with Singh \& Chavali in India who expressed that the commencement of fusion of clavicles from cadavers of known ages was seen early at 17 years and latest age for non union was 21 years; stage 2 began at 18 years until 23 years; stage 3 appeared at 18 years until 27 years; stage 4 at 19 years until 32 years with complete fusion at 22 years until 32 years. In addition; In America; study of Webb \& Suchey (1985) on cadavers mentioned that for males the medial clavicular epiphyses can lack an epiphysis through age 25 . Nonunion with a separate epiphysis occurred from ages 16 through 22 years. Partial union is found from ages 17 through 30 years. Complete union is first noted at age 21 years, with complete union in age 31 years. The ranges for the females contrast somewhat from those for the males. Nonunion without a separate epiphysis occurred through age 23 years. The age range for nonunion with a separate epiphysis is 16 through 21 years. Partial union reached out from age 16 to 33 years. Complete union started at age 20 , with complete union by age 34 years.

Furthermore; in India Gakhar et al. by using digital $\mathrm{X}$ - ray and CT specified that stage 2 appeared at 14 years in females and 15 years in males; stage 3 appeared at 17 years in both sexes; while stage 4 was observed at 20 years in females and 21 in males and stage 5 appeared at 25 years in females and 26 in males.

Moreover; in Spain, study of Garamendi et al. reported that stage 0 appeared at 5-15 years; stage 1 at $15-$ 18 years; stage 3 at $17-45$ years; stage 4 at $19-32$ years and stage 5 at $20-48$ years and stage 2 could not be appointed in any subject.

The differences between the age of ossification of the medial clavicular ends of previous studies and the current one is due to different methods used for assessment of the ossification; as they used either cadavers or X-ray which are not accurate tools and ossification could not be easily examined with them.

To best of our knowledge there is lack of Egyptian studies in this field except that done by El Gerby et al. on sample size of 130 subjects and age group (10-36 years); they expressed that stage 1 showed up at 14-19 years in males and 13-18 years in females; stage 2 began at 15-21 years in males and 14-20 years in females; stage 3 appeared at 16-23 years in males and 16-21 years in females; stage 4 observed at 19-24 in males and 18-24 years in females and stage 5 appeared at 21-26 years in males and 20-25 years in females. The differences between both Egyptian studies owing to different sample size and different age groups.

On contrary; studies of Kreitner et al. $(1997,1998)$ in Europe; proved that stage 1 showed up at 0-16 years; stage 2 started at 13-22 years; stage 3 started at 16-26 years and stage 4 started at 22-29 years. Moreover; in Thailand Pattamapaspong et al. reported that the age of appearance of stage 1 was from 11-16 years in both sexes; stage 2 appeared 14-21 in males and 12-19 in females; stage 3 appeared at 15-27 years in males and 16-26 years in females; stage 4 was observed at 17-26 years in males and 19-28 years in females and finally stage 5 appeared at 20-29 years in males and 23-29 years in females.

In Germany; a study done by Schulze et al. proved that stage 2 appeared at 16-24 years; stage 3 appeared at 16-25 years and stage 4 at 19-25 years. Another German study by Wittschieber et al. regarded that stage 1 appeared at 10-14 years in males and 12-15 years in females; stage 2 at 15-20 years in males and 14-18 years in females; stage 3 at 16-36 years in males and 15-26 years in females; stage 4 at 21-40 years in males and 21-37 years in females and stage 5 at 26-40 years in males and 26-39 years in females. In addition; Kellinghaus et al. (2010b) proved that stage 1 started at 10-15 in both sexes; stage 2 showed up at 14-20 years in males and 13-19 years in females; stage 3 appeared at 17-26 years in males and 16-26 years in females; stage 4 started at 21-35 years in both sexes and stage 5 started at 26-35 years in both sexes. While Kellinghaus et al. (2010a) stated that stage 2 showed up at 14-20 years in males and 13-18 years and stage 3 started at $17-20$ years in males and 16-22 years.

Finally, in Australia; Bassed et al. mentioned that stage 1 appeared at 13-20 years in males and 14-18 years in females; stage 2 at 14-22 years in males and 14-20 years in females; stage 3 at 16-23 years in both sexes; stage 4 at 18 26 at both sexes and stage 5 at 20-26 years in males and 2126 years in females.

The distinction in the ossification age between the present study and different studies could be explained by the effects of genetics; socio-economic status; nutrition; climate and environmental factors rather than ethnicity on the development (Kreitner et al., 1997).

Furthermore; the present work proved that CT with slice thickness 1-2 mm was much effective than those larger than $2 \mathrm{~mm}$ in studying the stages of ossification as the fine 
anatomical structures may be partially or completely masked due to partial volume effects; this was in agreement with Gurdeep et al. (2010) and Schulz et al. (2008).

\section{CONCLUSION}

From the current results it could be concluded that ossification of medial clavicular end could be used for age estimation either on right or left sides. The non-union of ossification centers could not be seen after 17 years and complete union could not be seen before 20 years. Also CT is a good visualization tool to be used. Furthermore; regression analysis for each and both clavicles in both sexes is specific to Egyptian population and should be used after validation of the results in other ones. The study recommended using stage 1 to be $<17$ years; stage 2 to be $>15$ years and $<18$ years; Stage 3 to be $>15$ years and $<23$ years; stage 4 of maturation to be $>19$ years and stage 5 to be $>21$ years.

In recommendation, further study covering all age groups specially those from 9-14 years and large sample size to establish with accuracy the age of ossification of each stage is recommended.

\section{ACKNOWLEDGEMENTS}

All personnel in the Radiology Department are acknowledged for allowing us to use their CT database for this research.

EL MORSI, D. A.; EL-ATTA, H. M. A.; ELMAADAWY, M.; TAWFIK, A. M. \& BATOUTY, N. H. Estimación de edad de osificación de la epífisis medial clavicular por tomografía computarizada. Int. J. Morphol., 33(4):1419-1426, 2015.

RESUMEN: El objetivo de esta investigación fue evaluar en la población egipcia, la exactitud de estimación de edad del desarrollo de la extremidad esternal de la clavícula, mediante tomografía computadorizada (TC), y desarrollar una fórmula discriminante que se pueda utilizar en egipcios. La investigación se realizó en 142 pacientes ( 84 hombres y 58 mujeres) después de obtener el consentimiento informado. Los pacientes fueron sometidos a TC de cortes múltiples en la extremidad esternal de la clavícula en ambos lados. Los resultados revelaron que la no unión fue observada entre los 8-17 años; la unión incompleta entre 15-20 años y la unión completa a los 20 años. Se concluye que la osificación de la extremidad esternal de la clavícula podría ser utilizada para la estimación de la edad utilizando la TC como herramienta de visualización. El análisis de regresión para ambas clavículas en los dos sexos es específico de la población egipcia y se debe utilizar después de validar los resultados. El estudio recomienda el uso de la etapa 1 en $<17$ años, etapa 2 en $>15$ años, etapa 3 en >15 años, etapa 4 en la maduración >19 años y la etapa 5 >21 años.

PALABRAS CLAVE: Ciencia forense; Estimación de la edad; Estado de osificación; Extremidad esternal de la clavícula; Tomografía computadorizada.

\section{REFERENCES}

Bassed, R. B.; Drummer, O. H.; Briggs, C. \& Valenzuela, A. Age estimation and the medial clavicular epiphysis: analysis of the age of majority in an Australian population using computed tomography. Forensic Sci. Med. Pathol., 7(2):148-54, 2011.

Brown, A. A.; Derkyi-Kwarteng, L. \& Amonoo-Kuofi, H. S. Study on the time frame for ossification of the medial clavicular epiphyseal cartilage by X-ray in Ghanaian students. Int $J$ Morphol., 31(2):491-6, 2013.

Cunha, E.; Baccino, E.; Martrille, L.; Ramsthaler, F.; Prieto, J.; Schuliar, Y.; Lynnerup, N. \& Cattaneo, C. The problem of aging human remains and living individuals: a review. Forensic Sci. Int., 193(1-3):1-13, 2009.

El-Gerby, K. M.; Mohammed, A. S. \& Gomaa, M. S. Using thinslice multidetector computed tomography in forensic age estimation based on the ossification status of the medial clavicular epiphysis among egyptian subjects. Med. J. Cairo Univ., 81(2):221-7, 2013.

Gakhar, G. K.; Gupta, V.; Jasuja, O. P. \& Khandelwal, N. Determining the ossification status of sternal end of the clavicle using CT and digital X-ray: A comparative study. J. Forensic Res., 5(2):1-6, 2014.

Garamendi, P. M.; Landa, M. I.; Botella, M. C. \& Alemán, I. Forensic age estimation on digital X-ray images: Medial epiphyses of the clavicle and first rib ossification in relation to chronological age. J. Forensic Sci., 56(Suppl. 1):S3-12, 2011.

Gurdeep, K.; Khandelwal, N. \& Jasuja, O. P. Computed tomographic studies on ossification status of medial epiphysis of clavicle: Effect of slice thickness and dose distribution. $J$. Indian Acad. Forensic Med., 32(4):298-302, 2010. 
Kellinghaus, M.; Schulz, R.; Vieth, V.; Schmidt, S. \& Schmeling, A. Forensic age estimation in living subjects based on the ossification status of the medial clavicular epiphysis as revealed by thin-slice multidetector computed tomography. Int. J. Legal Med., 124(2):149-54, 2010.

Kellinghaus, M.; Schulz, R; Vieth, V.; Schmidt, S.; Pfeiffer, H. \& Schmeling, A. Enhanced possibilities to make statements on the ossification status of the medial clavicular epiphysis using an amplified staging scheme in evaluating thin-slice CT scans. Int. J. Legal Med., 124(4):321-5, 2010.

Kreitner, K. F.; Schweden, F.; Schild, H. H.; Riepert, T. \& Nafe, B. Computerized tomography of the epiphyseal union of the medial clavicle: an auxiliary method of age determination during adolescence and the $3 \mathrm{~d}$ decade of life? Rofo, 166(6):4816, 1997.

Kreitner, K. F.; Schweden, F. J.; Riepert, T.; Nafe, B. \& Thelen, M. Bone age determination based on the study of the medial extremity of the clavicle. Eur Radiol., 8(7):1116-22, 1998.

Mühler, M.; Schulz, R.; Schmidt, S.; Schmeling, A. \& Reisinger, $\mathrm{W}$. The influence of slice thickness on assessment of clavicle ossification in forensic age diagnostics. Int. J. Legal Med., 120(1):15-7, 2006.

Pattamapaspong, N.; Madla, C.; Mekjaidee, K. \& Namwongprom, $\mathrm{S}$. Age estimation of a Thai population based on maturation of the medial clavicular epiphysis using computed tomography. Forensic Sci. Int., 246:123.e1-5, 2015.

Schmeling, A.; Reisinger, W.; Geserick, G. \& Olze, A. Age estimation of unaccompanied minors. Part I. General considerations. Forensic Sci. Int., 159 (Suppl. 1):S61-4, 2006.

Schulz, R.; Mühler, M.; Reisinger, W.; Schmidt, S. \& Schmeling, A. Radiographic staging of ossification of the medial clavicular epiphysis. Int. J. Legal Med., 122(1):55-8, 2008.

Schulz, R.; Schiborr, M.; Pfeiffer, H.; Schmidt, S. \& Schmeling, A. Sonographic assessment of the ossification of the medial clavicular epiphysis in 616 individuals. Forensic Sci. Med. Pathol., 9(3):351-7, 2013.

Schulze, D.; Rother, U.; Fuhrmann, A.; Richel, S.; Faulmann, G. $\&$ Heiland, M. Correlation of age and ossification of the medial clavicular epiphysis using computed tomography. Forensic Sci. Int., 158(2-3):184-9, 2006.

Singh, J. \& Chavali, K. H. Age estimation from clavicular epiphyseal union sequencing in a Northwest Indian population of the Chandigarh region. J. Forensic Leg. Med., 18(2):82-7, 2011.

Webb, P. A. \& Suchey, J. M. Epiphyseal union of the anterior iliac crest and medial clavicle in a modern multiracial sample of American males and females. Am. J. Phys. Anthropol., 68(4):457-66, 1985.
Wittschieber, D.; Schulz, R.; Vieth, V.; Küppers, M.; Bajanowski, T.; Ramsthaler, F.; Püschel, K.; Pfeiffer, H.; Schmidt, S. \& Schmeling, A. The value of sub-stages and thin slices for the assessment of the medial clavicular epiphysis: a prospective multi-center CT study. Forensic Sci. Med. Pathol., 10(2):1639, 2014.

\section{Correspondence to:}

Dr. Doaa El - Morsi

Assistant Professor of Forensic Medicine \& Clinical Toxicology

Department of Forensic Medicine \& Clinical Toxicology

Mansoura Faculty of Medicine

00201223872287

Mansoura

EGYPT

EMail: dr.doaa2014@outlook.com,

Received: 07-07-2015

Accepted: 21-09-2015 